\title{
К ВОПРОСУ О СООТНОШЕНИИ КАТЕГОРИЙ „ДЕЙКТИЧНОСТЬ” И „ФАСАДНОСТЬ”
}

\author{
ON THE QUESTION OF THE RELATIONSHIP BETWEEN \\ THE CATEGORIES OF "SPATIAL DEIXIS", “OBSERVER", "FACADE”
}

\author{
ЛЮДМИЛА ГОРБУНОВА
}

\begin{abstract}
This paper deals with the categories spatial deixis, observer, front. We distinguish two types of observer: Observer-speaker and Collective observer. Collective Observer is a necessary semantic category to understand the meanings of some linguistic units adequately. These units reflect the language community's understanding of what kind of orientation towards a particular object should be regarded as standard. Using language tools with locative semantics, the speaker applies different spatial strategies. The category of observer is required for all of these.
\end{abstract}

Людмила Горбунова, Иркутский государственный университет, Иркутск - Россия, ludgorbunova@mail.ru

Современная лингвистика активно использует термин наблюдатель, что вполне естественно для антропоцентрической парадигмы. Наблюдатель понимается как лищо, с позиции которого представляется ситуация. Использование огромного количества слов и морфем с пространственным значением невозможно без учета данной категории. В значения таких единиц встраивается наблюдатель, а корректная формулировка их семантики требует указания на дейктичность обозначаемой ситуации. Так, адъективные приставки за-, позади- / предимеют значение 'дальше / ближе от наблюдателя, чем $\mathrm{X}^{\prime}$ : залесный поселок, заозерный лес, заречные поля - предгорная местность, предмостный участок дороги) (см. подробно Горбунова 2010). В подобных случаях „взаиморасположение локализуемого предмета и локума определяется позицией наблюдателя [...]. Только контекст и положение наблюдателя уточняют, с какой именно реальной стороны [...] происходит что-л." (Всеволодова, Владимирский 1982: 218).

Например, значение прилагательных в следующих контекстах понимается с точки зрения наблюдателя-европейца:

1) В этом, пожалуй, его (англичанина) самое разительное отличие от заокеанского кузена. Дело не только в том, что американец... раньше уходит по утрам... (В. Овчинников). Перемещение наблюдателя относительно 
точки отсчета в подобных случаях ведет к тому, что та же единица начинает обозначать другой фрагмент пространства. Говорящий осознает это и рефлектирует на этот счет:

2) С точки зрения англичанина "заморские пришельцы" - это иберы, кельты, римляне, англы, саксы, юты и норманны, с точки зрения японцев - „американская эскадра командора Перри” (В. Овчинников).

Подобный тип ориентации у Ю.Д. Апресяна назван относительной ориентацией предметов в пространстве. Ей будет соответствовать дейктическая стратегия понимания, т. е. стратегия, учитывающая фигуру наблюдателя.

Ю.Д. Апресян выделяет и объекты с абсолютной ориентацией - фасадные (Апресян 1995а). Этот признак „приписывается именам предметов, имеющих такую выделенную сторону, через которую в норме осуществляется их использование" (Апресян, 1995б: 40). Человек, как правило, может располагаться только с фасадной стороны подобного объекта и отсюда оценивать пространственную конфигурацию: задиВанная пыль, зашкафный таракан, запрестольная икона, заиконный сверчок / преддиванный столик, предзеркальная подставка, предыконная лампада. Значения подобных единиц Ю.Д. Апресян предлагает формулировать следующим образом: „X находится с той стороны $\mathbf{Y}$, через которую У нормально используется'” и „'X находится со стороны $\mathbf{Y}$-а, противоположной той, через которую $\mathbf{Y}$ нормально используется" (Апресян 1995б) - и указывает на недейктичность подобных ситуаций, т. е. нерелевантность для них фигуры наблюдателя.

Отмеченные нами теоретические установки стали уже почти общим местом, аксиомой, не обсуждаемой в исследованиях. Однако тщательный анализ научной литературы и языкового материала приводит к мысли о том, что соотношение категорий дейктичность - фасадность - наблюдатель требует уточнения.

1. Начнем с того, что сам Ю.Д. Апресян указывает: говорящий, обозначая в речи локализацию объектов, может отражать пространство не так, как он сам его видит, а так, как оно могло бы видеться другому лицу, например, собеседнику. Анализируя ситуацию „пусть некто ищет авторучку, которая, по сведениям говорящего, лежит на телефонном столике сбоку от телефонного аппарата" (Апресян 1997: 278), автор пишет, что говорящий в этом случае отражает не свое видение ситуации, а то, как эту ситуацию видит адресат, как бы мысленно вставая рядом с адресатом.

2. При анализе значения английского соте Ю.Д. Апресян признает данный глагол таким дейктическим словом, для которого совпадение говорящего и наблюдателя в одном лице необязательно. 
Высказывание John will come home at five 'Джон придет домой в пять' может быть сделано человеком, который сам не собирается быть дома у Джона. Процесс перемещения Джона к дому может быть ориентирован относительно другого наблюдателя, которого говорящий мыслит дома у Джона и которому он эмпатизирует (Апресян 1997: 277-278).

Говорящий в этом случае опирается на чувственный опыт наблюдателя, которого он мыслит в пространстве и точку зрения которого отражает в высказывании. Следовательно, при использовании этого глагола говорящий и наблюдатель могут совпадать, но могут являться разными лицами, глагол же всегда отражает позицию наблюдателя.

3. Таким образом, говорящий с помощью некоторой языковой единицы может номинировать свое пространство (например, в случаях относительной ориентации). Однако частотны и случаи, когда, используя языковые средства, мы отражаем не свое видение ситуации, а видение наблюдателя, т. е. другого лица, что доказано А.В. Кравченко (Кравченко 1993). Более того, данный исследователь обосновывает доминирующую роль фигуры наблюдателя по сравнению с эгоцентризмом говорящего. Эта же мысль лежит в основе классификации функций говорящего, предложенной Е.В. Падучевой (Падучева 2011), а при анализе значения глагола показаться она прямо говорит: „В значение слова показаться входит не говорящий, а другой участник - наблюдатель" (Падучева 2011: 5). Важным является также утверждение Е.В. Падучевой о том, что лексическое значение данного слова отражает позицию наблюдателя, т. е. наблюдатель всегда „встроен” в значение независимо от того, какую позицию занимает говорящий и какой тип ситуации описывается в конкретном высказывании.

4. Анализ языкового материала позволяет говорить о неоднозначном соотношении категорий наблюдатель - фасадность - дейктичность.

Некоторые нефасадные объекты могут концептуализироваться как фасадные. Географические объекты не имеют стороны, через которую регулярно взаимодействуют с человеком, человек может перемещаться по отношению к каждому из них. При этом в ряде случаев фасадность им приписывается. Так, нами (Горбунова 2010) описаны оттопонимичные префиксально-суффиксальные прилагательные русского языка, значения которых отражают позицию человека, находящегося в центре России. Именно с этой точки зрения оценивается и толкуется локализация объекта в словарях и энциклопедиях: Заволжский экономический район 'располагающийся между Волгой, Уралом, Северным Уралом и Прикаспием', Закавказский военный округ 'лежащий к югу от Кавказа', зауральский массив 'находящийся к востоку от Урала'. Большое количество такого рода прилагательных позволило нам выделить категорию коллективный наблюдатель, который ориенти- 
руется в пространстве из исторически закрепленной точки, в качестве которой мыслится центр России. В данном случае локализация наблюдателя моделируется прилагательным как постоянная по отношению к объекту $\mathbf{X}$, а ориентацию в терминах Ю.Д. Апресяна можно назвать абсолютной, ведь интерпретация примеров не зависит от того, с какой стороны Байкала или Урала находится говорящий:

3) Предбайкальские буряты издавна жили в лесостепных районах долинах рек Ангары, Лены и их притоков (А. Семенова);

4) Но именно в таких условиях живет „зауральская" Россия, каждый регион которой по территории способен уместить по несколько Франций или Швейцарий (А. Попов, А. Ивантер).

Можно ли утверждать в этом случае, что концептуализация географических объектов как фасадных снимает дейктичность ситуации?

Как известно, дейктична та ситуация, для которой релевантна фигура наблюдателя. Релевантна ли она в указанном случае? Несомненно, поскольку правильно понять, о каком месте на географической карте идет речь, может только тот, кто знает, что наблюдатель, чья точка зрения отражена значением языковой единицы, располагается в центре России.

Единицы, значения которых фиксируют коллективное знание, не так уж редки. Рассмотрим употребление прилагательного правый 'находящийся справа от кого-л., чего-л.' . Довольно частотные употребления отражают относительную ориентацию, когда только знание о точки отсчета - позищии наблюдателя - позволяет понять, где именно расположен предмет:

5) На сколько повысится уровень воды в левой трубке, если в правую налить керосина столько, что он образует столб высотой Н=30 см? (В. Лукашик, Е. Иванова).

Не столь однозначно в аспекте обозначенной проблемы можно трактовать словосочетания правый берег реки или Правобережный округ 2. Иркутска, ведь в этом случае надо знать, что точкой отсчета является наблюдатель, стоящий по течению реки. Правой в авиационной терминологии называется часть самолета относительно направления полета. Во всех этих употреблениях позиция наблюдателя закреплена общественной договоренностью как постоянная по отношению к определенному виду объектов, следовательно, ориентация относительно них является абсолютной, а объекты (река, самолет) концептуализируются подобно фасадным. Однако без знания того, как принято ориентироваться относительно данного вида объектов, т. е. как располагается воображаемый наблюдатель, невозможно адекватно воспринимать высказывание. 
Еще более ярко релевантность позиции наблюдателя в случаях абсолютной ориентации можно продемонстрировать на примерах, фиксирующих „местный” опыт.

6) Продажа домов по правой стороне Байкальского тракта (из рекламы).

Пример 6) может понять только тот, кто знает, что правой считается сторона, находящаяся справа по ходу движения в сторону Байкала. Для людей, владеющих данной информацией, это случай абсолютной ориентации, а фигуру наблюдателя из ситуации устранить невозможно. Такого же рода употребления

7) Подготовка заднепровской операции затянулась почти на месяи (П.Н. Врангель);

8) Машина Ольги резко свернула В замоскворецкий переулок (Л. Зорин).

Говорящий часто учитывает, что адресат речи может быть не осведомлен об этой местной договоренности, и поэтому поясняет, уточняет локализацию объекта:

9) В основном это заречные районы - Ленинский и Канавинский, но есть объекты и в Московском, Советском и Нижегородском районах (М. Песин);

10) Зареченский район Тулы - район Тулы, находящийся $b$ северо-западной части города. Заречъе является одной из старейших частей Тулы (И. Семенов).

В подобных случаях коллективный наблюдатель, позиция которого зафиксирована в значении языковой единицы, - это не весь языковой коллектив, а его часть.

По отношению к классическим фасадным объектам типа картина, икона, зеркало также не всегда однозначно можно утверждать, что фасадностью снимается дейктичность ситуации. В целом ряде случаев можно отметить необходимость знаний о позиции наблюдателя, ведь фасадность определяется как сторона объекта, через которую в норме осуществляется его эксплуатация. В норме, т. е. обычно, чаще всего. (Кстати, знания о том, как нормально эксплуатируется объект, тоже базируются на коллективном опыте). Так, в норме этот мир, эта сторона понимается как 'мир людей', мир концептуализируется как фасадный объект. Однако, например, в романе В. Орлова Альтист Данилов наблюдатель находится по другую сторону границы миров, а контекст фиксирует эту необычную позищию:

11) Данилова в Девяти Слоях еще узнавали, шепотом просили рассказать земные анекдоты, но для многих он был уже пришельцем из потустороннего мира, демоном с того съета (В. Орлов).

Безоговорочную дейктичность в осознании локализации этого и того мира демонстрирует автор примера 12):

12) Подобно декадентским героям Уальда и Кэролла она живет сразу В двух мирах - закартинном и здешнем, но отнюдь не очевидно, который из двух является для нее потусторонним (Л. Попенко). 
5. Анализ языкового материала демонстрирует, что при отражении локализации говорящий может использовать различные пространственные стратегии, приписывая объекту фасадность или игнорируя ее. Дейктический характер ситуации не зависит от актуальности / неактуальности признака фасадность. В любом случае адресат должен знать, позицию какого типа наблюдателя имеет в виду говорящий - непосредственно воспринимающего объекты и ориентирующегося на себя (за горой течет река) или коллективного, фиксированная позиция которого разнообразно отражает опыт определенного социума.

\section{Библиография}

А п р е с я н Ю.Д., Дейксис в лексике и грамматике и наивная модель мира, „Семиотика и информатика" 1997, № 35, с. 272-298.

А п р е с я н Ю.Д., Избранные труды: 8 2-х томах, т. 1: Лексическая семантика, „Языки русской культуры", Москва 1995а.

А п р е с я н Ю.Д., Избранные труды: $b$ 2-х томах, т. 2: Интегральное описание языка и системная лексикография, „Языки русской культуры”, Москва 19956.

В с е в о л о д о в а М.В., В л а д и м и р с к и й Е.Ю., Способы выражения пространственных отношений в современном русском языке, „Русский язык”, Москва 1982.

Г о р б у н о в а Л.И., Когнитивный образ ситуации как основа семантической структуры языковой единицы (на материале единиц атрибутивно-локативной языковой модели): монография, изд-во ИГУ, Иркутск 2010.

К р а в ч е н к о А.В., К проблеме наблюдателя как системообразующего фактора $\mathrm{b}$ языке, „Известия РАН. Серия литературы и языка” 1993, т. 52, № 3, с. 45-56.

П а д у ч е в а Е.В., Эгоиентрические валентности и деконструкиия говорящего, „Вопросы языкознания" 2011, № 3, с. 3-18. 